\title{
Aplikasi Augmented Reality Perlengkapan Militer Menggunakan Algoritma FAST Corner Dan Lucas Kanade
}

\author{
Nanda Maulana Hidayat ${ }^{1}$, Agung Triayudi $^{2}$, Endah Tri Esti Handayani ${ }^{3}$ \\ ${ }^{1}$ Jurusan Informatika, Fakultas Teknologi Komunikasi dan Informatika, Universitas Nasional \\ ${ }^{2,3}$ Fakultas Teknologi Komunikasi dan Informatika, Universitas Nasional \\ e-mail: ${ }^{1}$ maulanananda554@gmail.com, ${ }^{2}$ agungtriayudi@ civitas.unas.ac.id, \\ 3endahtriesti@civitas.unas.ac.id
}

\begin{abstract}
Abstrak
Pengetahuan mengenai perlengkapan kemiliteran tidak hanya diperoleh melalui pameran saja, dengan adanya perkembangan teknologi informasi bisa diperoleh melalui aplikasi. Penggunaan aplikasi augmented reality dapat dijadikan contoh dalam pengetahuan perlengkapan militer secara tiga dimensi. Perancangan ini bertujuan memberikan pengetahuan kepada masyarakat umum dengan menggunakan teknologi Augmented Reality. Perancangan ini menggunakan metode ADDIE dan algoritma FAST Corner dan Lucas Kanade. Perancangan ini menghasilkan sebuah aplikasi yang berisi pengenalan perlengkapan militer yang terdiri dari baret, topi boonie, topi patroli, helm, kacamata, tas besar, P3K (Pertolongan Pertama Pada kecelakaan), pisau, senjata jauh dan senjata menengah. Informasi singkat mengenai masingmasing perlengkapan militer yang dirancang secara menarik agar masyarakat umum mudah memahami dalam menggunakan aplikasi yang dapat dijalankan pada platform Android.
\end{abstract}

Kata kunci- Augmented Reality, Edukasi, FAST Corner, Lucas Kanade.

\begin{abstract}
Knowledge of military equipment is not only obtained through exhibitions, with the development of information technology can be obtained through applications. The use of augmented reality applications can be used as an example in the knowledge of military equipment in three dimensions. This design aims to provide knowledge to the general public by using Augmented Reality technology. This design uses the ADDIE method and the FAST Corner and Lucas Kanade algorithms. The design resulted in an application containing the introduction of military equipment consisting of berets, Boonie hats, patrol hats, helmets, glasses, large bags, first aid kits (First Aid In accidents), knives, remote weapons, and medium weapons. Brief information about each military equipment is attractively designed to make the general public easy to understand in using applications that can be run on the Android platform.
\end{abstract}

Keywords-Augmented Reality, Education, FAST Corner, Lucas Kanade.

\section{PENDAHULUAN}

$\mathrm{P}$ engetahuan mengenai perlengkapan kemiliteran dapat diperoleh melalui pameran yang biasanya dilakukan pada acara peringatan Hari Ulang Tahun Kemerdekaan Indonesia (HUT RI). Namun dengan adanya Covid-19 yang berkepanjangan sehingga membatasi aktivitas, seperti ditiadakannya acara pameran dan kunjungan ke markas besar TNI, maka 
diperlukan aplikasi sebagai media berupa aplikasi Augmented Reality di bidang Militer.

Dari jurnal terdahulu dapat dijadikan relevansi terhadap Aplikasi Augmented Reality Pengenalan Senjata Militer Modern menggunakan Metode Marker Based Tracking oleh Muhammad Wildan Anandasyah dan Budi Arifitama, hasil dari aplikasi yaitu dapat memunculkan objek 3D Senjata[1]. Pada jurnal Perancangan Aplikasi Pengenalan Kendaraan Militer Augmented Reality dengan menggunakan Metode Marker Based Tracking yang dilakukan oleh Wahyu Satria Aji. Menghasilkan beberapa tahapan untuk membuat aplikasi yaitu, tahap pertama melakukan perancangan User Interface, tahap kedua memasukkan objek 3D kedalam Unity serta membuat marker dengan Vuforia dan tahap ketiga yaitu melakukan pengujian aplikasi menggunakan smartphone yang akan menampilkan berbagai macam kendaraan militer[2]. Kemudian pada jurnal Perancangan Aplikasi Augmented Reality Pengenalan Baret TNI Berbasis Android oleh Agung Taruna Ramadhan dan Hardianto. Hasil dari perancangan yang dilakukan dapat menampilkan produk tiga dimensi (3D) Baret [3].

Berdasarkan hasil dari relevansi yang didapat, maka akan dirancang aplikasi Augmented Reality Perlengkapan Militer menggunakan Metode ADDIE yang digunakan untuk proses perancangan bersifat sistematis dan interaktif. Selain itu, penggunaan algoritma FAST Corner dapat membaca sudut tepi. Sedangkan metode Lucas Kanade berguna dalam melacak objek tiga dimensi sehingga dapat menciptakan sebuah aplikasi yang lebih baik.

\section{METODE PENELITIAN}

\subsection{ADDIE Model}

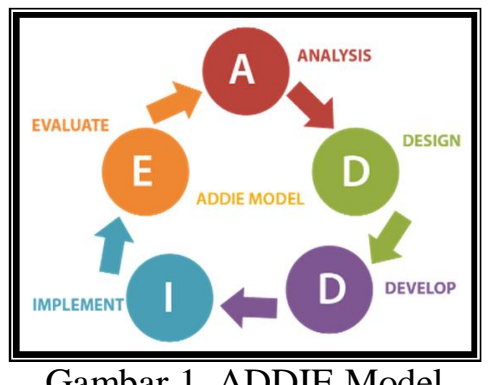

Penelitian ini menggunakan ADDIE Model untuk proses perancangan yang bersifat sistematis dan interaktif dan dinamis. Berikut tahapan pembangunan aplikasi Augmented Reality perlengkapan militer:

\subsubsection{Analysis (Analisis Kebutuhan)}

Pada tahapan analisis, proses ini yang mencakup segala kebutuhan baik itu pengumpulan data, pengumpulan objek dan material desain yang nantinya digunakan lebih lanjut dalam membuat aplikasi tersebut.

\subsubsection{Design (Desain)}

Dalam proses desain, perancang dapat berkreasi menyalurkan bakatnya dalam pembuatan aplikasi tersebut. Biasanya menggunakan software desain seperti figma untuk membuat tampilan User Interface serta Adobe Ilustrator dalam pembuatan desain dasar dan beberapa asset lainnya. Perihal desain objek tiga dimensi blender merupakan software yang cocok dalam pembuatan objek tiga dimensi. 


\subsubsection{Develop (Mengembangkan)}

Pada tahap ini semua dikumpulkan menjadi satu kesatuan seperti asset desain, objek tiga dimensi, desain User Interface, database, source code yang nantinya akan digabung dan di build sehingga menjadi sebuah aplikasi yang dapat digunakan.

\subsubsection{Implement (Penerapan)}

Pengujian biasanya dilakukan agar aplikasi berjalan sesuai aturan yang telah direncanakan. Pada tahap ini dibutuhkan tester atau sukarelawan untuk mencoba aplikasi beta untuk mengetahui hasil dari aplikasi tersebut sebelum di publish secara umum.

\subsubsection{Evaluate (Evaluasi)}

Dalam tahap akhir yaitu evaluasi, melakukan perbaikan apabila mengalami sesuatu yang diluar dugaan dan akan terus di tester kembali sampai aplikasi dapat berjalan sesuai dengan aturan yang direncanakan sehingga dapat digunakan bersama-sama [4].

\subsection{Analisis Kebutuhan Sistem}

Dalam proses penelitian tentunya membutuhkan alat-alat penunjang yang nantinya digunakan untuk mencapai hasil dari penelitian yang terdapat pada tabel 1 dan tabel 2.

Tabel 1. Perangkat Keras yang Digunakan

\begin{tabular}{l|l}
\multicolumn{1}{c}{ Perangkat } & \multicolumn{1}{c}{ Kuantitas } \\
\hline Processor & Intel Core i5 9400F \\
Memory $($ RAM $)$ & 8 GB \\
GPU & Radeon RX 570 8GB \\
SSD & Adata 256 GB
\end{tabular}

Pada tabel 1 mendeskripsikan tentang perangkat keras beserta kuantitasnya yang dilakukan untuk memenuhi kebutuhan sistem.

Tabel 2. Perangkat Lunak yang Digunakan

\begin{tabular}{c}
\hline Perangkat Lunak \\
\hline Blender \\
Unity \\
Figma \\
Adobe Ilustrator \\
Visual Studio 2017 \\
\hline
\end{tabular}

Pada tabel 2 mendeskripsikan tentang perangkat lunak yang digunakan untuk memenuhi kebutuhan untuk merancang aplikasi perlengkapan militer.

\subsection{Flowchart Aplikasi}

Perancangan urutan proses pada aplikasi perlengkapan militer. Berikut adalah flowchart secara garis besar pada aplikasi. 


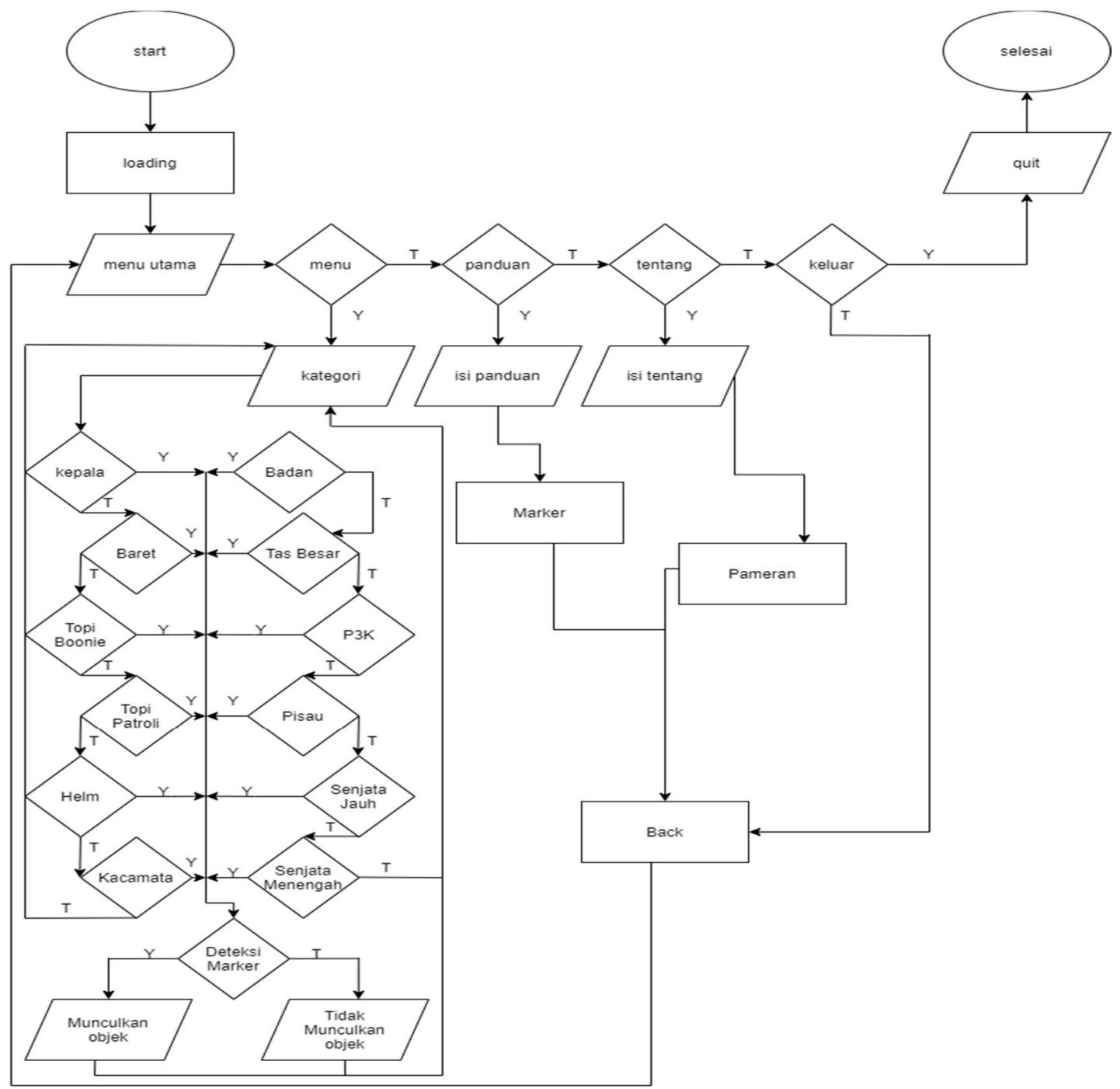

Gambar 2. Flowchart Aplikasi

Pada gambar 2 menjelaskan urutan proses dari aplikasi. Ketika aplikasi di jalankan dan proses loading selesai, maka akan menuju ke dalam tampilan Menu. Dalam tampilan Menu terdapat beberapa menu pilihan yaitu Tentang, Panduan, dan Kategori Menu. Pada Kategori dibedakan menjadi dua bagian yaitu Menu Kepala dan Badan. Setelah memilih kategori, kemudian user memilih marker perlengkapan untuk di scan. Setelah objek tiga dimensi atau marker yang di scan telah muncul, akan keluar keterangan dan terdapat beberapa pilihan gestur untuk melihat objek secara detail. Setelah selesai melihat perlengkapan maka dapat menuju video pameran yang ada di Menu Tentang. Pada marker terdapat dua pilihan, yaitu berada di dalam Menu Panduan maupun dalam bentuk buku.

\subsection{Marker}

Augmented Reality menggunakan bantuan kamera untuk melacak penanda. Pelacakan berbasis penanda ini memiliki perbedaan ataupun pola yang unik sebagai perbedaan dengan penanda lainya perihal dalam menghasilkan objek tiga dimensi [5]. Marker berupa gambar dua dimensi memiliki dua jenis sebagai penanda, yaitu marker-based tracking yang menggunakan marker dan Markerless tanpa adanya marker. Penelitian ini menggunakan marker-based 
tracking yang single marker yang dimana didalam satu marker gambar dua dimensi hanya terdapat satu objek tiga dimensi saja berlawanan dengan multiple marker [6]. Hasil dari Augmented Reality tergantung pada penilaian bintang yang memiliki interval 0 sampai 5, semakin tinggi bintang maka semakin cepat objek tiga dimensi terbaca oleh kamera. Berikut adalah marker yang digunakan dalam aplikasi augmented reality perlengkapan militer yang berada didalam database vuforia SDK.

Tabel 3. Marker pada Vuforia

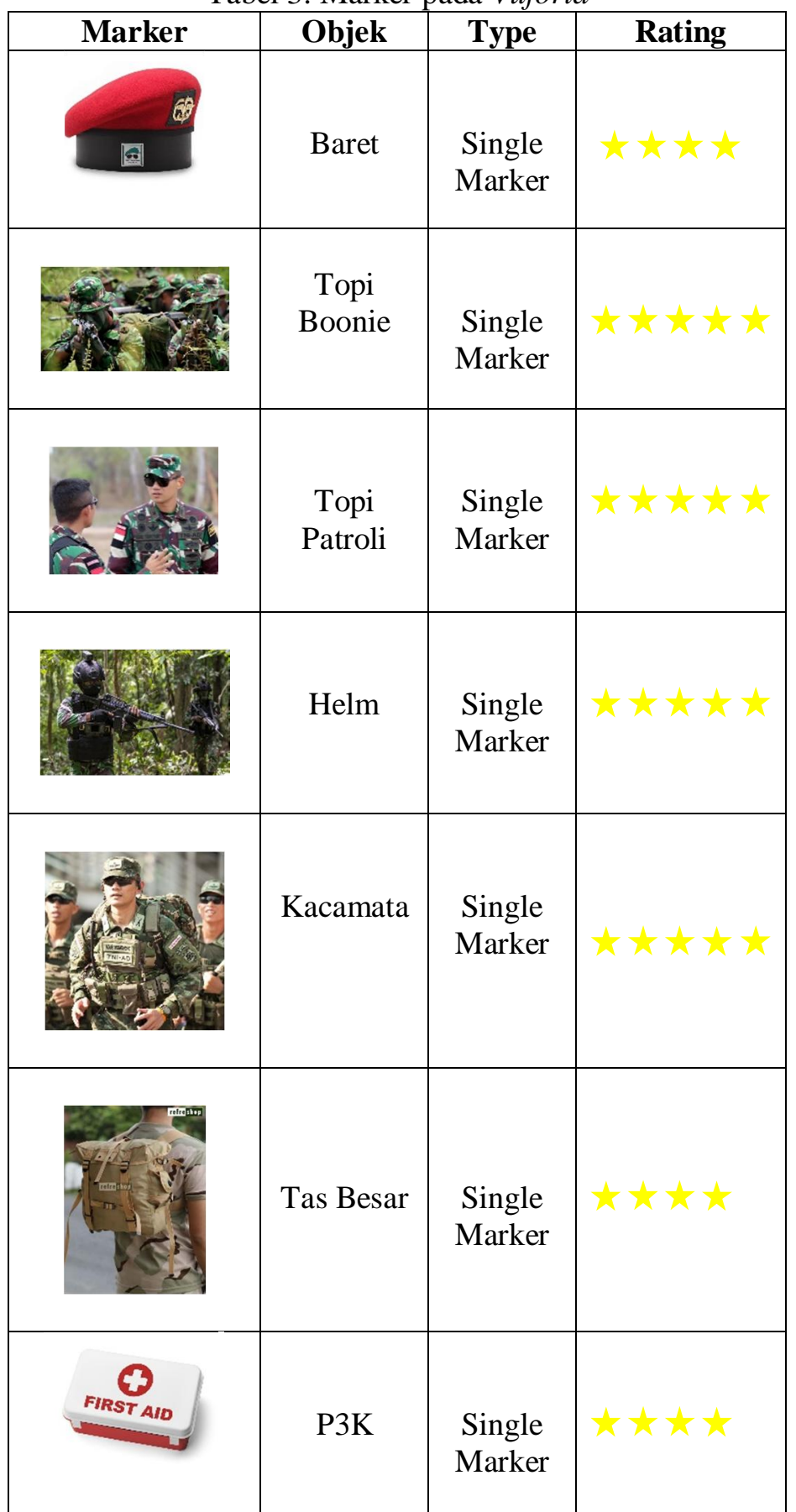

Nanda, et., al [Aplikasi Augmented Reality Perlengkapan Militer Menggunakan Algoritma FAST Corner dan Lucas Kanade] 


\begin{tabular}{|c|c|c|c|}
\hline & Pisau & $\begin{array}{l}\text { Single } \\
\text { Marker }\end{array}$ & 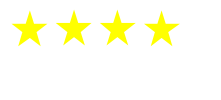 \\
\hline$\frac{1}{12}=\frac{3}{1}$ & $\begin{array}{c}\text { Senjata } \\
\text { Jauh }\end{array}$ & $\begin{array}{l}\text { Single } \\
\text { Marker }\end{array}$ & $\star \star x \star$ \\
\hline$t^{*}=$ & $\begin{array}{c}\text { Senjata } \\
\text { Menengah }\end{array}$ & $\begin{array}{l}\text { Single } \\
\text { Marker }\end{array}$ & 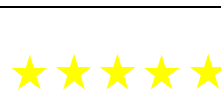 \\
\hline
\end{tabular}

\subsection{Vuforia Engine}

Vuforia memiliki peran penting dalam membangun aplikasi Augmented Reality, Vuforia dapat mengenali dan melacak marker secara realtime. Vuforia memiliki library yang digunakan dalam membuat penelitian ini yaitu FAST Corner dan Lucas Kanade, SDK Vuforia dapat menjembatani vuforia dan unity dengan menggunakan akses Vuforia AR Extension For Unity. Selain itu vuforia terus dikembangkan oleh Qualcomm agar Augmented Reality dapat terus berkembang [7].

\subsection{FAST Corner Detection}

Algoritma FAST (Feature from Accelerated Segment Test) Corner Detection penentuan sudut tepi untuk mendeteksi sudut-sudut. Algoritma FCD bertujuan untuk mempercepat waktu saat melakukan komputasi secara realtime sehingga menurunkan tingkat akurasi pendeteksian sudut [8]. Algoritma ini membutuhkan 4 titik dari 16pixel dengan membandingkan intensitas titik pixel dari titik p (pusat). Berikut ini tahapan proses algoritma FCD.
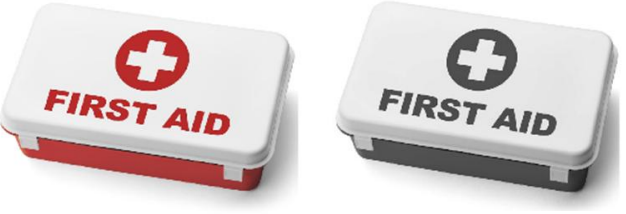

Gambar 3. Tampilan Mode Grayscale

Pada gambar 4 menampilkan perbandingan marker normal dan marker yang telah di ubah ke dalam mode grayscale.

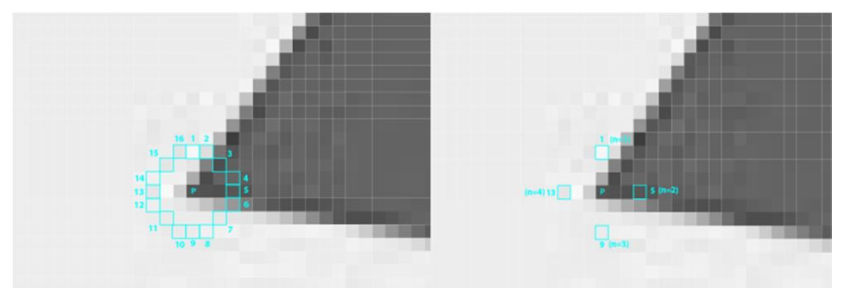

Gambar 4. Menentukan Titik Pusat dari 16pixel 
Pada gambar 4 menentukan titik pusat lokasi dari 16pixel dengan masing-masing 3 radius kemudian 4 titik dibandingkan dengan intensitas titik pusat p. Apabila terdapat paling sedikit memenuhi tiga kategori yang ditetapkan dalam algoritma FCD yaitu:

$$
S_{p \rightarrow \mathrm{x}}=\left\{\begin{array}{lrc}
d, & I_{p \rightarrow \mathrm{x}} \leq I_{p}-t & \text { gelap } \\
\mathrm{s}, I_{p}-t< & I_{p \rightarrow \mathrm{x}}<I_{p}+t & \text { normal }(1) \\
\mathrm{b}, & I_{p}+t \leq I_{p \rightarrow \mathrm{x}} & \text { terang }
\end{array}\right.
$$

Apabila paling sedikit 3 titik yang memenuhi 3 kategori yang ditetapkan dalam algoritma FAST Corner Detection akan diproses di Vuforia Engine SDK dan dianggap sebagai titik unik sehingga dapat menampilkan objek tiga dimensi [9].

\subsection{Lucas Kanade}

Lucas Kanade berperan sebagai pelacakan dalam objek tiga dimensi yang berhasil ditampilkan oleh kamera setelah membaca marker tersebut. Algoritma ini mampu mendeteksi transformasi citra seperti rotasi dan lekukan sehingga apabila marker dipindahkan maka objek tiga dimensi akan mengikuti pergerakan marker. Lucas Kanade menentukan posisi titik fitur pada bingkai sebelumnya ke bingkai berikutnya. Perpindahan titik oleh Lucas Kanade menggunakan persamaan [10]:

$$
\left[\begin{array}{l}
x+u \\
y+v
\end{array}\right]=\left[\begin{array}{ll}
a_{1} & a_{2} \\
a_{3} & a_{4}
\end{array}\right]\left[\begin{array}{l}
x \\
y
\end{array}\right]+\left[\begin{array}{l}
a_{5} \\
a_{6}
\end{array}\right](2)
$$

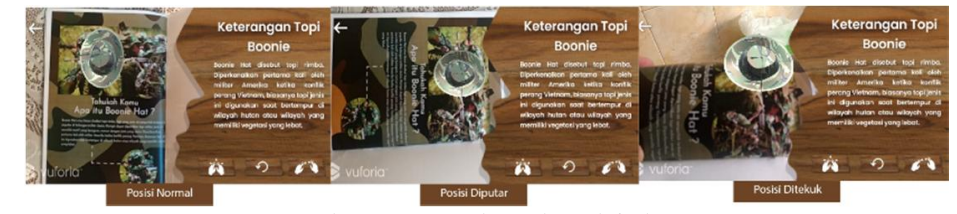

Gambar 5. Melacak Objek 3D

Pada gambar 6 memperlihatkan proses melacak objek dengan mengikuti pergerakan marker yang bertransformasi.

\section{HASIL DAN PEMBAHASAN}

\subsection{Implementasi Graphical User Interface (GUI)}

Setelah melewati rangkaian tahapan rancangan akhirnya sampai pada tahapan pengembangan dari User Interface dan User Experience. Implementasi Graphical User Interface terhadap aplikasi perlengkapan militer. Berikut ini merupakan tampilan grafis.

\begin{tabular}{|c|c|c|}
\hline No & Tampilan & Penjelasan \\
\hline 1 & & $\begin{array}{l}\text { Pada tampilan Loading } \\
\text { Screen, tunggu sampai bar } \\
\text { terisi penuh dan akan menuju } \\
\text { tampilan Menu Utama. }\end{array}$ \\
\hline
\end{tabular}

Tabel 4. Tampilan pada Aplikasi 


\begin{tabular}{|c|c|c|}
\hline 2 & Daprence & $\begin{array}{l}\text { Pada Menu Utama berisi } \\
\text { beberapa menu pilihan seperti; } \\
\text { Tentang, Panduan dan Menu. }\end{array}$ \\
\hline 3 & & $\begin{array}{l}\text { Pada Menu Panduan berisi tata } \\
\text { cara menggunakan aplikasi. } \\
\text { Selain itu juga dapat } \\
\text { mengunduh marker. }\end{array}$ \\
\hline 4 & $=$ & $\begin{array}{l}\text { Pada Menu Tentang berisi } \\
\text { tujuan dari pembuatan aplikasi } \\
\text { perlengkapan militer, serta } \\
\text { terdapat pilihan } \\
\text { Pameran. }\end{array}$ \\
\hline 5 & & $\begin{array}{l}\text { Pada Menu Pameran berisi } \\
\text { video perlengkapan militer. }\end{array}$ \\
\hline 6 & & $\begin{array}{l}\text { Pada Menu Marker berisi } \\
\text { gambar perlengkapan militer } \\
\text { yang sudah terintegrasi dengan } \\
\text { aplikasi. }\end{array}$ \\
\hline 7 & 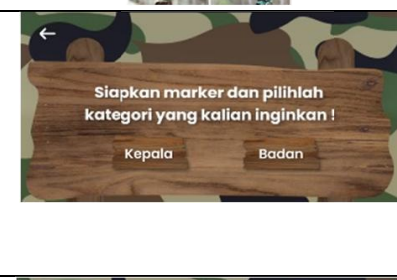 & $\begin{array}{l}\text { Pada Menu Katagori, berisi } \\
\text { pilihan Menu Kepala dan } \\
\text { Badan. Pada Menu tersebut } \\
\text { terdapat marker yang sudah } \\
\text { dipisahkan } \\
\text { kategori. }\end{array}$ \\
\hline 8 & & $\begin{array}{l}\text { Pada Menu Badan terdapat } \\
\text { beberapa pilihan, diantaranya: } \\
\text { Tas Besar, P3K, Pisau, Senjata } \\
\text { Jauh, Senjata Menengah. }\end{array}$ \\
\hline 9 & & $\begin{array}{l}\text { Pada Menu Kepala terdapat } \\
\text { beberapa pilihan, diantaranya; } \\
\text { Baret, Topi Boonie, Topi } \\
\text { Patroli, Helm, Kacamata. }\end{array}$ \\
\hline 10 & 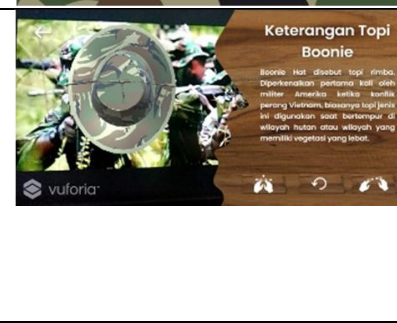 & $\begin{array}{l}\text { Pada Tampilan Topi Boonie, } \\
\text { kamera diarahkan ke marker } \\
\text { agar dapat menampilkan objek } \\
\text { tiga dimensi. Selain itu } \\
\text { terdapat keterangan serta } \\
\text { gestur untuk objek seperti; } \\
\text { rotasi, perbesar, dan perkecil. }\end{array}$ \\
\hline
\end{tabular}




\begin{tabular}{|l|l|l|}
\hline 11 & \multicolumn{1}{|c|}{$\begin{array}{l}\text { Setelah selesai menaluan } \\
\text { aplikasi, pada tombol keluar } \\
\text { terdapat notifikasi untuk } \\
\text { konfirmasi pengguna sebelum } \\
\text { mengakhiri penelusurannya. }\end{array}$} \\
\hline 12 & $\begin{array}{l}\text { Selain dapat mengunduh } \\
\text { marker dalam aplikasi juga } \\
\text { disediakan marker dalam } \\
\text { bentuk buku. }\end{array}$ \\
\hline
\end{tabular}

\subsection{Pengujian Aplikasi}

Dalam tahap ini dilakukan pengujian aplikasi kepada beberapa sukarelawan dengan menggunakan smarthphone serta versi android yang berbeda sebagai perbandingan. Dapat dilihat perbandingan smartphone yang berbeda dalam tabel 5 .

Tabel 5. Smartphone yang Digunakan

\begin{tabular}{|c|c|}
\hline Perangkat & Versi Android \\
\hline Xiaomi Note 5 & $9($ Pie $)$ \\
\hline Oppo F7 & 10 \\
\hline Samsung M20 & $8($ Oreo $)$ \\
\hline
\end{tabular}

Pada Tabel 5 menjelaskan bahwa perangkat yang digunakan dalam pengujian aplikasi ini antara lain; Xiaomi Note 5 versi android 9, Oppo F7 dengan versi 10 serta Samsung M20 dengan versi android 8.

\subsection{Hasil Pengujian Aplikasi}

Untuk mendapatkan penilaian untuk aplikasi ini maka dilakukan pengujian menggunakan tiga smartphone dengan sistem pengujian yang berbeda. Berikut hasil pengujian, antara lain:

\subsubsection{Hasil Pengujian Jarak}

Tabel 6. Hasil Pengujian Jarak

\begin{tabular}{|c|c|c|}
\hline Perangkat & $\begin{array}{c}\text { Jarak } \\
\text { Minimum }\end{array}$ & $\begin{array}{c}\text { Jarak } \\
\text { Maksimum }\end{array}$ \\
\hline Xiaomi Note 5 & $\pm 7 \mathrm{~cm}$ & $\pm 40 \mathrm{~cm}$ \\
\hline Oppo F7 & $\pm 5 \mathrm{~cm}$ & $\pm 60 \mathrm{~cm}$ \\
\hline Samsung M20 & $\pm 5 \mathrm{~cm}$ & $\pm 50 \mathrm{~cm}$ \\
\hline
\end{tabular}

Dalam tabel 6 adalah hasil dari pengujian jarak. Hasil dari pengujian jarak tersebut diantaranya; Xiaomi Note 5 memiliki jarak minimum $\pm 7 \mathrm{~cm}$ dengan jarak maksimum $\pm 40 \mathrm{~cm}$, Oppo F7 dengan Samsung M20 memiliki jarak minimum yaitu $\pm 5 \mathrm{~cm}$ dan memiliki jarak maksimum $\pm 60 \mathrm{~cm}$ untuk Oppo F7 dan \pm 50 untuk Samsung M20. 


\subsubsection{Hasil Pengujian Respon Objek}

Tabel 7. Hasil Pengujian Respon Objek

\begin{tabular}{|c|c|}
\hline Perangkat & Respon Objek \\
\hline Xiaomi Note 5 & $\pm 1,7$ detik \\
\hline Oppo F7 & $\pm 1,6$ detik \\
\hline Samsung M20 & $\pm 1,4$ detik \\
\hline
\end{tabular}

Pada tabel 7 telah dilakukan pengujian respon objek terhadap tiga smartphone berbeda dengan menghasilkan waktu yang cepat $<2$ detik untuk menampilkan objek. Hasil yang didapat diantaranya; Xiaomi Note $5 \pm 1,7$ detik, Oppo F7 $\pm 1,6$ detik serta Samsung M20 dengan $\pm 1,4$ detik.

\subsubsection{Hasil Pengujian Cahaya}

Tabel 8. Hasil Pengujian Cahaya

\begin{tabular}{|c|c|c|c|}
\hline Perangkat & $\begin{array}{c}\text { Redup } \\
\text { (Tanpa Cahaya) }\end{array}$ & Normal & $\begin{array}{c}\text { Terang } \\
\text { (Ring Light) }\end{array}$ \\
\hline Xiaomi Note 5 & Terdeteksi & $\pm 1,7$ detik & $\pm 2,1$ detik \\
\hline Oppo F7 & Tidak Terdeteksi & $\pm 1,6$ detik & $\pm 2,4$ detik \\
\hline Samsung M20 & Tidak Terdeteksi & $\pm 1,4$ detik & $\pm 2,5$ detik \\
\hline
\end{tabular}

Pada tabel 8 telah dilakukan pengujian terhadap cahaya. Dikarenakan faktor cahaya memiliki peran besar dalam aplikasi ini, maka dalam menggunakan aplikasi ini dibutuhkan pencahayaan yang cukup agar dapat menampilkan objek tiga dimensi.

\section{KESIMPULAN}

Berdasarkan pengujian pada Augmented Reality Perlengkapan Militer dapat diambil kesimpulan bahwa:

1) Aplikasi Augmented Reality Perlengkapan Militer dapat mempermudah masyarakat dalam mempelajari dan melihat perlengkapan militer tanpa harus datang ke acara pameran.

2) Metode $A D D I E$ digunakan untuk proses perancangan yang bersifat sistematis dan interaktif, selain itu, penggunaan algoritma FAST Corner dapat membaca sudut tepi. Sedangkan metode Lucas Kanade berguna dalam melacak objek tiga dimensi dapat menciptakan sebuah aplikasi yang lebih baik.

3) Hasil dari pengujian jarak smartphone terhadap marker, Oppo F7 lebih unggul dengan mendapatkan jarak maksimum $\pm 60 \mathrm{~cm}$ dari $\pm 5 \mathrm{~cm}$ dari jarak minimum. Pada tahap pengujian respon, Samsung M20 lebih unggul yaitu \pm 1 ,6detik untuk dapat menampilkan objek. Pada pengujian Intensitas Cahaya Xiaomi Note 5 dapat menampilkan objek dengan cahaya yang minim akan tetapi objek sulit untuk di deteksi. Jadi, Oppo F7 lebih unggul dalam kondisi cahaya normal sedangkan dalam kondisi terang Xiaomi Note 5 lebih unggul. 


\section{SARAN}

Saran untuk penelitian selanjutnya penulis dapat mengembangkan Augmented Reality ini menjadi Mixed Reality dan juga dapat menggunakan virtual button untuk navigasinya.

\section{DAFTAR PUSTAKA}

[1] M. W. Anandasyah and B. Arifitama, 2020. "Aplikasi Augmented Reality Pengenalan Senjata Militer Modern Menggunakan Marker Based Tracking," Senamika, Vol. 1, No. 1, pp. 502-506,

[2] W. S. Aji, 2020. “Jurnal Teknologi Informasi, Vol. 6 No. 1 Juni 2020 Perancangan Aplikasi Pengenalan Kendaraan Militer Dengan Augmented Reality Menggunakan Marker Based Tracking Application of Military Vehicle Recognition Application With Jurnal Teknologi Informasi," Vol. 6, No. 1, pp. 28-34,

[3] A. Patrian, "Perancangan Aplikasi Augmented Reality Pengenalan Candi Nusantara Berbasis Android," pp. 149-158.

[4] Y. Yulianti, L. K. Wardhani, A. R. Hakim, S. D. Aji, and M. N. Hudha, 2021, "Augmented Reality (AR) subject Natural Science Media For Human Framework Topics," IOP Conf. Ser. Mater. Sci. Eng., Vol. 1098, No. 3, p. 032032, doi: $10.1088 / 1757-899 x / 1098 / 3 / 032032$.

[5] S. Sendari, D. Anggreani, M. Jiono, A. Nurhandayani, and C. Suardi, 2020, "Augmented Reality Performance In Detecting Hardware Components Using Marker Based Tracking Method," 4th Int. Conf. Vocat. Educ. Training, ICOVET 2020, pp. 175-179, doi: 10.1109/ICOVET50258.2020.9229895.

[6] M. E. Apriyani, M. Huda, and S. Prasetyaningsih, 2016 "Analisis Penggunaan Marker Tracking pada Augmented Reality Huruf Hijaiyah,” J. INFOTEL - Inform. Telekomun. Elektron., Vol. 8, No. 1, p. 71, , doi: 10.20895/infotel.v8i1.54.

[7] G. Y. Abdillah, S. Andryana, and A. Iskandar, 2020 "Augmented Reality Sebagai Media Pembelajaran Perangkat Keras Komputer Dengan Fast Corner dan Natural Feature Tracking," JIPI (Jurnal Ilm. Penelit. dan Pembelajaran Inform., Vol. 5, No. 2, p. 79, , doi: 10.29100/jipi.v5i2.1767.

[8] N. Wahyudi, R. A. Harianto, and E. Setyati, 2019, "Augmented Reality Marker Based Tracking Visualisasi Drawing 2D ke dalam Bentuk 3D Dengan Metode FAST Corner Detection," J. Intell. Syst. Comput., Vol. 1, No. 1, pp. 9-18, [Online]. Available: https://jurnal.istts.ac.id/index.php/INSYST/article/view/28.

[9] Z. Cai, Y. Ou, Y. Ling, J. Dong, J. Lu, and H. Lee, 2020 "Feature Detection and Matching With Linear Adjustment and Adaptive Thresholding," IEEE Access, Vol. 8, pp. 189735-189746, , doi: 10.1109/ACCESS.2020.3030183. 
[10] M. Yusuf and A. Gunaryati, 2021. "Teknologi Mixed Reality pada Aplikasi Tuntunan Shalat Maghrib Menggunakan Algoritma Fast Corner Detection dan Lucas Kanade," Vol. 06, pp. 82-93, 